ORIGINAL ARTICLE

\title{
Early discharge and readmission to hospital in the first month of life in the Northern Region of the UK during 1998: a case cohort study
}

\author{
S J Oddie, D Hammal, S Richmond, L Parker
}

Arch Dis Child 2005;90:119-124. doi: 10.1136/adc.2003.040766

See end of article for authors' affiliations

......................

Correspondence to: Dr S J Oddie, Higher Specialist Trainee in Neonatology, Neonatal Unit, Royal Victoria Infirmary, Queen Victoria Road, Newcastle upon Tyne NE1 4LP, UK; samoddie@doctors.org.uk

Accepted

17 February 2004
Aims: To study the frequency and associations of early postpartum discharge and infant readmission to hospital.

Methods: Infants readmitted to hospital during the first 28 days of life in 1998 in the Northern Region of the UK were studied.

Results: A total of 4743 of 11338 (42\%) babies were discharged on or before the first postnatal day. Rates of early discharge varied significantly between hospitals. Infants $<2500 \mathrm{~g}$ at birth (adjusted odds ratio (AOR) $0.44,95 \% \mathrm{Cl} 0.29$ to 0.66 ), infants $35-37$ weeks gestation at birth (AOR $0.65,95 \% \mathrm{Cl} 0.49$ to 0.86 ), and firstborn infants (AOR $0.09,95 \% \mathrm{Cl} 0.08$ to 0.10 ) were less likely to be discharged early. Women from more deprived areas were more likely to be discharged early (AOR $1.37,95 \% \mathrm{Cl} 1.12$ to 1.67). A total of 907 of 32015 (2.8\%) babies liveborn in the region were readmitted to hospital during 1998. Readmission rates varied significantly by hospital of birth but not by timing of discharge. Babies $<2500 \mathrm{~g}$ at birth (AOR 1.95, 95\% Cl 1.16 to 3.28) and babies born at 35-37 weeks gestation (AOR $1.72,95 \% \mathrm{Cl} 1.15$ to 2.57 ) were more likely to be readmitted. Breast fed babies were less likely to be readmitted (AOR $0.69,95 \% \mathrm{Cl} 0.53$ to 0.90 ). Infants initially discharged early were not more likely to be readmitted.

Conclusions: Early discharge occurred variably in the Northern Region in 1998. It is not associated with readmission to hospital. Breast feeding is associated with lower rates of readmission to hospital.
$\mathrm{S}$ ince 1958 average postpartum hospital stays have declined from around ten days to under three days. ${ }^{1}$ After similar changes in North America, researchers have shown in large retrospective studies that shorter postpartum stays are associated with an increase in early infant readmission to hospital, with odds ratios of 1.3 for risk of readmission where there was early postpartum discharge. ${ }^{2}{ }^{3}$ These data, and the strong opinions they gave rise to $^{45}$ contributed to the passing of federal and state legislation mandating provision of a minimum 48 hour postpartum hospital stay, or home care in the United States. ${ }^{6}$ However, several subsequent studies, including a very large casecontrol study, have not shown that so called "early discharge" is associated with an increased risk of neonatal readmission..$^{7-10}$

Information on neonatal readmission in the UK is confined to a series of papers published between 1959 and 1967,,,$^{11-14}$ which described shortening maternity stays in one UK city and increased rates of readmission, particularly with feeding problems. However, little other published UK data on this subject exists. Recent UK literature has concentrated on serious feeding difficulties, particularly hypernatraemic dehydration, and a link has been made between this uncommon problem and early discharge. ${ }^{15}$

In this study we analyse the prevalence and predictors of early discharge, and examine any relation with later readmission in the North of England.

\section{METHODS}

\section{Early discharge}

Five large maternity units delivered $48 \%$ of all 32015 babies born in the former Northern Region of the UK during 1998. We used all available data from patient administration systems on births in these hospitals, but excluded babies born at $<35$ weeks gestation and any baby subsequently readmitted. We analysed anonymised data on the date of birth, gestation, mode of delivery, maternal age, parity, birth weight, date of discharge, method of feeding at initial hospital discharge, and postcode at time of delivery from representative portions of 1998 births. We analysed these control data using logistic regression to determine factors associated with early discharge. We entered factors significant at univariate level $(\mathrm{p}<0.1)$ into the model. We excluded cases with incomplete data from the logistic regression.

We defined early discharge as discharge on the day of birth or the day after the day of birth.

\section{Readmissions}

We defined readmission to include both paediatric and neonatal units, but not reviews in outpatient clinics, emergency departments, or paediatric day units unless these resulted in overnight stay. We included admissions occurring after midnight and before 0900 even if they were discharged on the same calendar date. We excluded elective, second, and subsequent readmissions.

We identified all babies readmitted to any of the 14 hospitals that admit children in the former Northern Region before the age of 29 days during the calendar year 1998 by interrogating hospital information departments. One member of the team (SO) reviewed each set of notes to confirm eligibility and extract data. The diagnosis was taken from the clinical notes or discharge letter and recorded parental anxiety as the primary diagnosis only if no other diagnosis was made and notes indicated a significant level of parental concern, including maternal psychiatric disease. Infants born 
Table 1 Factors associated with early discharge among infants born in five maternity units in the Northern Region of the UK during 1998

\begin{tabular}{|c|c|c|c|c|c|c|}
\hline \multirow[b]{2}{*}{ Variable } & \multicolumn{3}{|c|}{ Univariate } & \multicolumn{3}{|c|}{ Multivariate* $^{*}$} \\
\hline & $\mathbf{n}$ & $\begin{array}{l}\text { Odds ratio } \\
(95 \% \mathrm{Cl})\end{array}$ & $\begin{array}{l}\text { Likelihood ratio } \\
\text { test } \\
\text { p value }\end{array}$ & $\mathbf{n}$ & $\begin{array}{l}\text { Odds ratiot } \\
(95 \% \mathrm{Cl})\end{array}$ & $\begin{array}{l}\text { Likelihood ratio } \\
\text { test } \\
\mathrm{p} \text { value }\end{array}$ \\
\hline Unit of delivery & 11338 & & $<0.0001$ & & & $<0.0001$ \\
\hline Hospital 1 & 3217 & 1 & & 1902 & 1 & \\
\hline Hospital 2 & 1763 & 1.56 (1.39 to 1.75$)$ & & 1481 & 2.08 (1.75 to 2.46$)$ & \\
\hline Hospital 3 & 840 & 0.81 (0.69 to 0.95$)$ & & 644 & $0.78(0.63$ to 0.97$)$ & \\
\hline Hospital 4 & 2467 & $0.99(0.89$ to 1.11$)$ & & 2091 & $1.13(0.96$ to 1.31$)$ & \\
\hline Hospital 5 & 3051 & $1.00(0.91$ to 1.11$)$ & & & $-\S$ & \\
\hline Mode of delivery & 9974 & & $<0.0001$ & & & $<0.0001$ \\
\hline Normal vaginal & 8565 & 1 & & 5152 & 1 & \\
\hline Assisted vaginal & 1409 & $0.21(0.18$ to 0.24$)$ & & 966 & $0.50(0.42$ to 0.61$)$ & \\
\hline Caesarean section & & $-\ddagger$ & & & & \\
\hline Gestation (weeks) & 8157 & & $<0.0001$ & & & 0.001 \\
\hline $35-37$ & 595 & $0.62(0.52$ to 0.74$)$ & & 348 & $0.65(0.49$ to 0.86$)$ & \\
\hline $38-40$ & 5196 & 1 & & 3955 & & \\
\hline$>40$ & 2366 & 0.89 (0.81 to 0.99$)$ & & 1815 & $1.13(0.98$ to 1.29$)$ & \\
\hline Parity & 7270 & & $<0.0001$ & & & $<0.0001$ \\
\hline Primiparous & 3452 & $0.11(0.10$ to 0.12$)$ & & 2759 & $0.09(0.08$ to 0.10$)$ & \\
\hline Multiparous & 3818 & 1 & & 3359 & 1 & \\
\hline Maternal age (years) & 11338 & & $<0.0001$ & & & 0.04 \\
\hline$<20$ & 1434 & $0.46(0.40$ to 0.52$)$ & & 788 & 1.11 (0.89 to 1.38$)$ & \\
\hline $20-24$ & 2554 & $0.91(0.82$ to 1.01$)$ & & 1380 & $1.01(0.85$ to 1.21$)$ & \\
\hline $25-29$ & 3477 & 1 & & 1849 & 1 & \\
\hline $30-34$ & 2652 & 1.02 (0.92 to 1.12$)$ & & 1475 & $0.84(0.71$ to 1.00$)$ & \\
\hline$>35$ & 1221 & $1.06(0.93$ to 1.21$)$ & & 626 & $0.77(0.62$ to 0.96$)$ & \\
\hline Birth weight & 8284 & & $<0.0001$ & & & $<0.0001$ \\
\hline$<2500 \mathrm{~g}$ & 294 & $0.40(0.31$ to 0.53$)$ & & 161 & $0.44(0.29$ to 0.66$)$ & \\
\hline $2500-4499 \mathrm{~g}$ & 7854 & 1 & & 5864 & 1 & \\
\hline$>4499 \mathrm{~g}$ & 136 & $0.82(0.58$ to 1.16$)$ & & 93 & $0.50(0.32$ to 0.79$)$ & \\
\hline Feeding at hospital discharge & 8137 & & $<0.0001$ & & & 0.003 \\
\hline Formula & 4674 & 1 & & 3508 & 1 & \\
\hline Breast & 3368 & $0.73(0.67$ to 0.80$)$ & & 2555 & $0.87(0.76$ to 1.00$)$ & \\
\hline Mixed & 95 & $0.57(0.37$ to 0.88$)$ & & 55 & $0.39(0.21$ to 0.74$)$ & \\
\hline Deprivation quintile & 11203 & & $<0.0001$ & & & 0.008 \\
\hline 1 & 2251 & 1 & & 1321 & 1 & \\
\hline 2 & 2239 & $1.03(0.91$ to 1.16$)$ & & 1206 & $1.07(0.89$ to 1.30$)$ & \\
\hline 3 & 2239 & 1.26 (1.12 to 1.42$)$ & & 1178 & 1.27 (1.04 to 1.55$)$ & \\
\hline 4 & 2223 & $1.52(1.35$ to 1.71$)$ & & 1170 & 1.35 (1.10 to 1.65$)$ & \\
\hline 5 & 2251 & 1.73 (1.54 to 1.95$)$ & & 1243 & $1.37(1.12$ to 1.67$)$ & \\
\hline
\end{tabular}

in one hospital and readmitted to another, and inter-hospital transfers were followed.

To identify risk factors for readmission we confined the analysis to those 408 readmitted babies born in any one of the five large maternity units, irrespective of where the baby was readmitted. We linked the readmission rate with the data on early discharge and the associated factors previously listed. We carried out univariate and multivariate analyses as previously described, with early discharge considered among potential risk factors for readmission.

We subdivided readmission cases into those where there was a clear organic diagnosis (such as serious infection, potentially life threatening malformation, or surgical condition such as pyloric stenosis) underlying the readmission, and those we could not infer such clear organic diagnosis from the admission notes.

We allocated each birth to a census enumeration district and calculated a Townsend score. The Townsend score is a method which uses census data to attribute a community level deprivation score on the basis of postcode. ${ }^{16}$ We ranked the enumeration districts by deprivation score and divided them into quintiles by population with quintile 5 being the most deprived.

We present results as odds ratios and 95\% confidence intervals. We used the statistical package Stata 8.0 for the analysis.

\section{RESULTS}

\section{Early discharge (table 1)}

A total of 32015 babies were born alive in the region during 1998. We obtained control data for 11406 births of the 15200 births in the five maternity units occurring during 1998. We could not abstract data from some units for certain time periods. Table 2 shows rates of early discharge for the maternity units.

A total of 4743 of 11338 (42\%) infants were discharged early. Infants were discharged on a median of day 2 (interquartile range $1-3$ ), where day 0 was the day of birth. The five units differed significantly in their rates of early

Table 2 Rates of discharge on day of birth or day after birth by hospital of birth

\begin{tabular}{llll}
\hline $\begin{array}{l}\text { Maternity unit } \\
\text { of delivery }\end{array}$ & $\begin{array}{l}\text { Number } \\
\text { discharged }\end{array}$ & $\begin{array}{l}\text { No. early } \\
\text { discharges }\end{array}$ & Rate/1000 \\
\hline 1 & 3217 & 1303 & 405 \\
2 & 1763 & 908 & 515 \\
3 & 840 & 299 & 356 \\
4 & 2467 & 996 & 404 \\
5 & 3051 & 1237 & 405 \\
\hline
\end{tabular}


discharge. The magnitude of this observation is enhanced when confounding variables are taken into account (AOR $2.08,95 \%$ CI 1.75 to 2.46 ). Babies delivered by assisted vaginal delivery were significantly less likely to be discharged early (AOR $0.50,95 \%$ CI 0.42 to 0.61 ) and no babies born by caesarean section were discharged early.

Infants were less likely to be discharged early if they were born to a primiparous mother, born at 35-37 weeks gestation and if they were of low birth weight (table 1). Younger mothers were discharged early less often than older mothers, but when confounding variables were taken into account this association was reversed, with older women significantly less likely to be discharged early.

Breast feeding was associated with a reduction in early discharge (OR $0.73,95 \%$ CI 0.67 to 0.80 ), but when confounding variables were taken into account, this relation was of less statistical significance (AOR 0.87, 95\% CI 0.76 to $1.00)$.

Finally deprivation was associated with early discharge. The women from areas with most deprived Townsend scores were more likely to be discharged early compared to those from areas with the least deprived scores (AOR 1.37, 95\% CI 1.12 to 1.67$)$.

\section{Readmissions}

Nine hundred and seven infants $(2.8 \%)$ were readmitted to hospitals in the region at less than 29 days of age during 1998.

"Infections" accounted for the largest number of readmissions. In many of these the notes recorded no evidence for significant infection. The "other" group included pyloric stenosis, "colic", concern about possible convulsions, and cases where no problems at all were identified. In 141 cases there was evidence of a feeding problem in the medical or nursing notes. Among the 81 jaundiced babies phototherapy was administered in 69 cases. Thirty four babies had serum bilirubin of over $340 \mu \mathrm{mol} / \mathrm{l}$, and in 12 this value exceeded $400 \mu \mathrm{mol} / \mathrm{l}$. One baby had an exchange transfusion for haemolytic disease. Diagnoses associated with vomiting, principally gastro-oesophageal reflux, were the primary diagnoses in 54. Twenty eight infants were readmitted principally for congenital malformations, of which 19 were first diagnosed at this admission. Medical notes were generally of a poor quality and diagnoses were sometimes only mentioned in the nursing notes. Duration of admissions was generally short (median 2 days, range 0-32 days).

Readmissions took place at a median age of 14 days with no significant variation in frequency of admission by day of life.

\section{Case cohort analysis of factors associated with readmission}

Table 3 lists the primary readmission diagnoses for those 408 readmitted infants born in hospitals for which control data are available. Ninety three per cent of these 408 infants were readmitted to their hospitals of birth, with just five (1\%) initially readmitted to a hospital more than 10 miles from their birth hospital. These 408 infants form the cases for a case control analysis of the factors associated with readmission.

Multivariate analysis showed that only hospital of delivery, gestation, and mode of feeding were independently associated with admission to hospital in the first 28 days of life, while birth weight was of borderline significance (table 4). Although in univariate analysis early discharge was associated with a reduced risk of readmission (OR 0.75, 95\% CI 0.60 to 0.93 ), multivariate analysis showed that there was no independent relation between early discharge and readmission in the main dataset. Deprivation was associated with
Table 3 Diagnoses associated with 408 first readmissions to hospital during first 28 days among babies born in one of five maternity units for which control data were available in 1998

\begin{tabular}{lccc}
\hline & $\begin{array}{l}\text { Cases with } \\
\text { clear } \\
\text { organic } \\
\text { diagnosis }\end{array}$ & $\begin{array}{l}\text { Cases with no } \\
\text { clear organic } \\
\text { diagnosis }\end{array}$ \\
$\begin{array}{l}\text { No. of } \\
\text { diagnosis }\end{array}$ & 8 & 0 & 8 \\
\hline $\begin{array}{l}\text { Parental anxiety alone } \\
\text { Malformation }\end{array}$ & 14 & 13 & 1 \\
Vomiting & 25 & 0 & 25 \\
Jaundice & 28 & 2 & 26 \\
Apparently life threatening & 42 & 0 & 42 \\
event & 72 & 0 & 72 \\
Feeding problem & 89 & 50 & 39 \\
Other & 130 & 60 & 70 \\
Infections & & & \\
\hline
\end{tabular}

an increased rate of readmission in the univariate analysis, but multivariate analysis showed no independent association. Maternity unit 3 had a low rate of early discharge (AOR $0.78,95 \%$ CI 0.63 to 0.97 ), but had a high rate of readmissions even after deprivation and other confounders were considered (AOR 2.31, 95\% CI 1.59 to 3.35). Breast feeding at initial hospital discharge was predictive of a significantly lower rate of readmission in univariate and multivariate analyses (AOR $0.69,95 \%$ CI 0.53 to 0.90 ).

In order to investigate any potential relation between early discharge and readmissions soon after birth, we carried out a further case control analysis considering only those admissions occurring at less than 15 days of age. The results were similar to those in the analysis of the whole dataset except that breast feeding at initial hospital discharge was no longer associated with a reduced risk of readmission to hospital (data not shown).

To assess whether any relation existed between readmissions of lower "medical seriousness" we repeated the analysis considering only those readmissions where no clear organic diagnosis was made. Table 5 presents the results of this multivariate analysis. In this model we found a statistically significant relation between early discharge and reduced readmission (AOR $0.73,95 \%$ CI 0.54 to 0.99 ).

\section{DISCUSSION}

This retrospective case cohort study shows that rates of early postpartum discharge vary across our region and that early discharge occurs more commonly in women from more deprived areas. Readmission rates too vary greatly between hospitals and by mode of feeding at discharge. Early discharge is not associated with an increased risk of readmission in this study.

Our study is one of few among the extensive worldwide literature to be reported from the UK. ${ }^{11-14}{ }^{17}$ Ascertainment of cases of readmission is likely to be high. ${ }^{18}$ Our case definition was robust, met only by infants admitted to a paediatric ward for a clinically relevant period. A single experienced paediatrician confirmed each readmission, and movements within the region were followed.

However, as the study was retrospective, a limitation is that detailed information concerning exact diagnoses was sometimes limited in the notes. We believe that feeding problems were under-ascertained by admitting staff. For example, extreme weight loss was not always commented on in the medical record. This lack of precision limits the interpretations that can be drawn from our data. 
Table 4 Risk factors for any readmission to hospital at $<29$ days of age in 408 readmissions and 11406 controls taken from five maternity units in the Northern Region of the UK

\begin{tabular}{|c|c|c|c|c|c|c|}
\hline & \multicolumn{3}{|l|}{ Univariate } & \multicolumn{3}{|l|}{ Multivariate $^{*}$} \\
\hline & $\begin{array}{l}\text { n } \\
\text { Cases/controls }\end{array}$ & $\begin{array}{l}\text { Odds ratio } \\
(95 \% \mathrm{CI})\end{array}$ & $\begin{array}{l}\text { Likelihood } \\
\text { ratio test } \\
\text { p value }\end{array}$ & $\begin{array}{l}n \\
\text { Cases/controls }\end{array}$ & $\begin{array}{l}\text { Odds ratio } \\
\text { (95\% CI) }\end{array}$ & $\begin{array}{l}\text { Likelihood ratio } \\
\text { test } \\
\text { p value }\end{array}$ \\
\hline Unit of delivery & 11814 & & 0.001 & & & 0.0003 \\
\hline Hospital 1 & $101 / 3222$ & 1 & & $89 / 3076$ & 1 & \\
\hline Hospital 2 & $65 / 1765$ & $1.17(0.86$ to 1.61$)$ & & $61 / 1747$ & $1.25(0.90$ to 1.74$)$ & \\
\hline Hospital 3 & $55 / 841$ & 2.09 (1.49 to 2.92$)$ & & $45 / 743$ & 2.31 (1.59 to 3.35$)$ & \\
\hline Hospital 4 & $91 / 2484$ & $1.17(0.88$ to 1.56$)$ & & $77 / 2327$ & $1.42(1.03$ to 1.97$)$ & \\
\hline Hospital 5 & $96 / 3094$ & $0.99(0.75$ to 1.31$)$ & & & $-\ddagger$ & \\
\hline Mode of delivery & 11798 & & 0.38 & & & \\
\hline Normal vaginal & $298 / 8620$ & 1 & & $207 / 5928$ & & \\
\hline Assisted vaginal & $41 / 1415$ & 0.84 (0.60 to 1.17$)$ & & $29 / 1069$ & & \\
\hline Caesarean section & $53 / 1371$ & $1.12(0.83$ to 1.51$)$ & & $33 / 896$ & & \\
\hline Gestation (weeks) & 8571 & & $<0.0001$ & & & 0.001 \\
\hline $35-37$ & $57 / 596$ & 1.92 (1.42 to 2.59 ) & & $37 / 542$ & 1.72 (1.15 to 2.57$)$ & \\
\hline $38-40$ & $260 / 5213$ & & & $178 / 5054$ & & \\
\hline$>40$ & $74 / 2371$ & $0.63(0.48$ to 0.81$)$ & & $57 / 2297$ & $0.70(0.51$ to 0.95$)$ & \\
\hline Parity & 7678 & & 0.13 & & & \\
\hline Primiparous & $167 / 3459$ & 0.85 (0.69 to 1.05 ) & & $112 / 3253$ & & \\
\hline Multiparous & $217 / 3835$ & 1 & & $148 / 3677$ & & \\
\hline Maternal age (years) & 11794 & & 0.96 & & & \\
\hline$<20$ & $53 / 1444$ & 1.10 (0.79 to 1.52$)$ & & $30 / 982$ & & \\
\hline $20-24$ & $90 / 2569$ & 1.05 (0.79 to 1.38 ) & & $65 / 1720$ & & \\
\hline $25-29$ & $117 / 3493$ & 1 & & $87 / 2440$ & & \\
\hline $30-34$ & $89 / 2665$ & $1.00(0.75$ to 1.32$)$ & & $60 / 1906$ & & \\
\hline$>35$ & $39 / 1235$ & $0.94(0.65$ to 1.36$)$ & & $29 / 845$ & & \\
\hline Birth weight & 8704 & & $<0.0001$ & & & 0.05 \\
\hline$<2500 \mathrm{~g}$ & $36 / 295$ & 2.71 (1.89 to 3.89 ) & & $20 / 237$ & 1.95 (1.16 to 3.28$)$ & \\
\hline $2500-4499 \mathrm{~g}$ & $355 / 7876$ & 1 & & $249 / 7525$ & & \\
\hline$>4499 \mathrm{~g}$ & $4 / 138$ & $0.64(0.24$ to 1.75$)$ & & $3 / 131$ & 0.75 (0.24 to 2.40$)$ & \\
\hline Feeding at hospital discharge & 8522 & & 0.004 & & & 0.007 \\
\hline Formula & $247 / 4681$ & 1 & & $183 / 4564$ & 1 & \\
\hline Breast & $127 / 3370$ & $0.71(0.57$ to 0.89$)$ & & $88 / 3242$ & $0.69(0.53$ to 0.90$)$ & \\
\hline Mixed & $2 / 95$ & $0.40(0.10$ to 1.63$)$ & & $1 / 87$ & 0.27 (0.04 to 1.97$)$ & \\
\hline Deprivation quintile & 11648 & & 0.03 & & & \\
\hline$i$ & $65 / 2264$ & 1 & & $52 / 1779$ & & \\
\hline 2 & $60 / 2251$ & $0.93(0.65$ to 1.33$)$ & & $39 / 1552$ & & \\
\hline 3 & $73 / 2255$ & $1.13(0.80$ to 1.58$)$ & & $55 / 1511$ & & \\
\hline 4 & $82 / 2241$ & $1.27(0.92$ to 1.77$)$ & & $58 / 1477$ & & \\
\hline 5 & $97 / 2260$ & $1.49(1.09$ to 2.06$)$ & & $68 / 1574$ & & \\
\hline Early discharge & 11721 & & 0.01 & & & \\
\hline No & $249 / 6595$ & 1 & & $169 / 4515$ & & \\
\hline Yes & $134 / 4743$ & $0.75(0.60$ to 0.93$)$ & & $103 / 3378$ & & \\
\hline
\end{tabular}

The five maternity units had varying rates of early discharge. Unit 3 had a lower rate of early discharge. If unit 3 is excluded from the analysis the findings of the multivariate analysis are broadly similar.

We were disappointed that we were not able to include all the deliveries in some of the five maternity units in the control dataset. The exclusion of these data may have limited the statistical power of the study or even, arguably, introduced bias. As data were unavailable for specific time epochs, rather than on account of missing computer records or notes, we think this unlikely.

Additionally we would have preferred to have access to control data from more than just five maternity units which represented just $48 \%$ of 1998 births in the region. It is possible, but not in our view likely, that those maternity units for which control data were available differ in important respects from those for which no control data were available. Were this the case, the case control aspects of the study might not be generalisable to the rest of the region in 1998, nor more widely. However, even if it were argued that the five maternity hospitals from which we drew our controls were in some way unrepresentative of the region, we have still shown that the practices of birth hospitals are strongly and independently associated with risk of readmission.
Finally, a limitation of our study design was the use of community level deprivation scores, which will underestimate deprivation variations between individuals. We may therefore have underestimated the associations between deprivation and early discharge and missed a true association between readmission and deprivation.

We have shown a substantial variation in the practice of early discharge and also of readmission between different maternity units of birth that is not explained by characteristics of the mother or the baby. North American studies have shown such variations between centres, as well as variations in readmission rates between centres. ${ }^{8} 1019$ However some such studies have shown a link between higher early discharge rates and readmission. ${ }^{19}$

That early discharge seems to occur more commonly in more deprived groups is a striking finding, not explained by the characteristics of the mother or the baby. Where this has been described in North America it has been linked with payment structures not relevant to our population. The reasons for this unexpected relation between socioeconomic status and early discharge are unclear and further research is required to understand why these decisions occur.

Primiparous women were less likely to have been discharged early. That infants born to primiparous women 


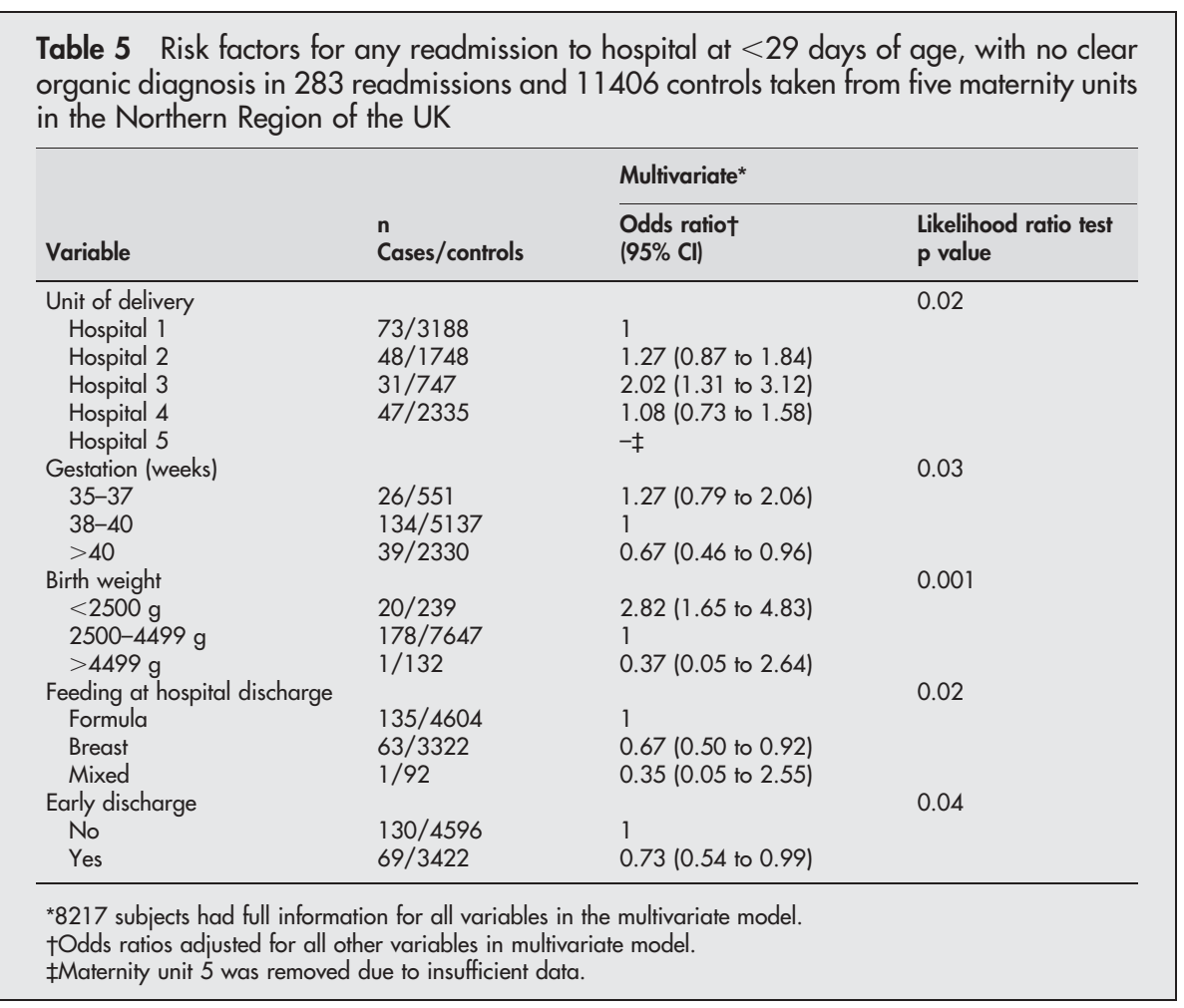

were not at increased risk of readmission could reflect appropriate postpartum management. Similarly maternal age predicts early discharge but not readmission, which might reflect appropriate decision making about timing of postpartum discharge.

The central finding that early discharge is not associated with readmission is counter to much, ${ }^{23}{ }^{9}$ but not all that is in the literature. ${ }^{7}{ }^{10}$ Indeed for admissions that were not at the higher end of the "seriousness" spectrum, early discharge seems to be associated with a decreased risk of readmission. In comparing these results with the mostly North American literature, we must bear in mind that maternity services in the UK have a different structure and history to those elsewhere. Midwives in the UK have a statutory obligation to visit, assess, and manage newborns at home after initial postpartum discharge regardless of the timing of discharge. Reports from North America show that feeding difficulties are a frequent diagnosis at readmissions associated with early discharge. ${ }^{9-21}$ That we have not shown an association with early discharge and readmission may be consistent with appropriate community management of these problems in the UK. In North America one study has shown that community management can moderate an association between early discharge and readmission. ${ }^{22}$

Furthermore, that jaundice underlay so comparatively few readmissions in our study may reflect a differing approach to the management of neonatal jaundice in the UK. ${ }^{23}$

Readmission occurred in many cases where discharge had not been early. This finding is consistent with some studies in the literature which suggest that where there are problems identified in hospital, the postpartum stay is appropriately prolonged, but the problems still may precipitate later readmission. ${ }^{10}$

It is striking and reassuring that infants who were breast fed at hospital discharge were no more likely to be readmitted to hospital in the first 15 days of life and were only $70 \%$ as likely to be readmitted in the first month. This finding persisted in the less "serious" admission subgroup analysis.
North American studies have found that breast feeding is associated with an increased risk of readmission. ${ }^{20} 24$ Neonatal readmissions in North America are dominated by jaundice. ${ }^{81}$ The difference between these studies and ours might be explained by differing midwifery practices in the UK. Alternatively, it might reflect UK management of the physiological jaundice that is commonly associated with difficulties in initiating breast feeding.

However, the finding of lower risk of readmission among breast fed infants should be interpreted with caution. Although we have shown that deprivation is not independently associated with readmission, our measure of deprivation is crude, and our models may therefore underestimate the effects of deprivation on risk of readmission. It is established $^{1}$ that breast feeding is associated with lower levels of deprivation and we cannot discount that intention to formula feed is acting as a marker for deprivation in these models.

It is striking that we were unable to explain either the variation in early discharge rates or the variation in readmission rates between hospitals within the data we collected. One hospital discharged twice as many women early as another, without any increased risk of readmission after controlling for known confounders. Another discharged fewer than average women early and yet had twice as many readmissions. Such associations may reflect variability in medical and midwifery culture, rather than the characteristics of the mothers and their babies. Variations in practice are not cost neutral to health organisations nor to families so, although this retrospective study does not provide evidence to support indiscriminate use of early discharge, it does argue for prospective and preferably randomised studies to study policies for early discharge and readmission.

\section{ACKNOWLEDGEMENTS}

Records clerks and administrative staff all over the region provided invaluable assistance. Dr E Hey and Mr A McNay contributed greatly to the planning and analysis of the study. 


\section{Authors' affiliations}

S J Oddie, Neonatal Unit, Royal Victoria Infirmary, Newcastle upon Tyne, UK

D Hammal, L Parker, Paediatric and Lifecourse Epidemiology Research Group, School of Clinical Medical Sciences, University of Newcastle, Sir James Spence Institute, Royal Victoria Infirmary, Newcastle Upon Tyne, UK

S Richmond, Neonatal Unit, Sunderland Royal Hospital, Sunderland, UK

Funding: The analysis of the data was supported by a grant from the special trustees of Newcastle upon Tyne Hospitals NHS Trust.

Competing interests: none declared

\section{REFERENCES}

1 Macfarlane A, Henderson J, Furtado A, et al. Birth counts, Vol. 2, 2nd edn. Norwich: The Stationary Office, 2000:541-3.

2 Braveman P, Kessel W, Egerter S, et al. Early discharge and evidence-based practice. Good science and good judgment. JAMA 1997;278:334-6.

3 Liu LL, Clemens CJ, Shay DK, et al. The safety of newborn early discharge. The Washington State experience. JAMA 1997;278:293-8.

4 Sacchetti AD, Gerardi M, Sawchuk P, et al. Boomerang babies: emergency department utilization by early discharge neonates. Pediatr Emerg Care 1997; 13:365-8.

5 Charles S, Prystowsky B. Early discharge, in the end: maternal abuse, child neglect, and physician harassment. Pediatrics 1995;96:746-7.

6 Anon. Newborns and mothers health protection act of 1996 (HR-3666). In: Title VI of pubic law 1996:104-204.

7 Madden JM, Soumerai SB, Lieu TA, et al. Effects of a law against early postpartum discharge on newborn follow-up, adverse events, and HMO expenditures. N Engl J Med 2002;347:2031-8.

8 Kotagal UR, Atherton HD, Eshett R, et al. Safety of early discharge for Medicaid newborns. JAMA 1999:282:1150-6.

9 Danielsen B, Castles AG, Damberg CL, et al. Newborn discharge timing and readmissions: California, 1992-1995. Pediatrics 2000;106:31-9.
10 Sword WA, Watt S, Krueger PD, et al. Understanding newborn infant readmission: findings of the Ontario Mother and Infant Survey. Can J Public Health 2001;92:196-200.

11 Anon. A survey of 100 early-discharge cases. Lancet 1966;1:536-40.

12 Arthurton MW, Bamford FN. Paediatric aspects of the early discharge of maternity patients. BMJ 1967;3:517-20

13 Craig GA, Muirhead JM. Obstetric aspects of the early discharge of maternity patients. BMJ 1967;3:520-2.

14 Theobald G. Home on the second day: the Bradford experiment. The combined maternity scheme. BMJ 1959;2:1364-7.

15 Laing IA, Wong CM. Hypernatraemia in the first few days: is the incidence rising? Arch Dis Child Fetal Neonatal Ed 2002;87:F158-62.

16 Townsend P, Beattie A. Health and deprivation: inequality and the North London: Routledge, 1988.

17 Braveman P, Egerter S, Pearl M, et al. Problems associated with early discharge of newborn infants. Early discharge of newborns and mothers: a critical review of the literature. Pediatrics 1995:96:716-26.

18 Oddie SJ, Richmond S, Coulthard M. Hypernatraemic dehydration and breast feeding: a population study. Arch Dis Child 2001;85:318-20.

19 Liu S, Wen SW, McMillan D, et al. Increased neonatal readmission rate associated with decreased length of hospital stay at birth in Canada. Can J Public Health 2000:91:46-50.

20 Edmonson MB, Stoddard JJ, Owens LM. Hospital readmission with feeding related problems after early postpartum discharge of normal newborns. JAMA 1997; 278:299-303.

21 Radmacher P, Massey C, Adamkin D. Hidden morbidity with "successful" early discharge. J Perinatol 2002;22:15-20.

22 Meikle SF, Lyons E, Hulac P, et al. Rehospitalizations and outpatient contacts of mothers and neonates after hospital discharge after vaginal delivery. Am J Obstet Gynecol 1998;179:166-71.

23 Dodd KL. Neonatal jaundice-a lighter touch. Arch Dis Child 1993;68:529-32.

24 Seidman DS, Stevenson DK, Ergaz Z, et al. Hospital readmission due to neonatal hyperbilirubinemia. Pediatrics 1995:96:727-9.

25 Soskolne El, Schumacher R, Fyock C, et al. The effect of early discharge and other factors on readmission rates of newborns. Arch Pediatr Adolesc Med 1996; 150:373-9.

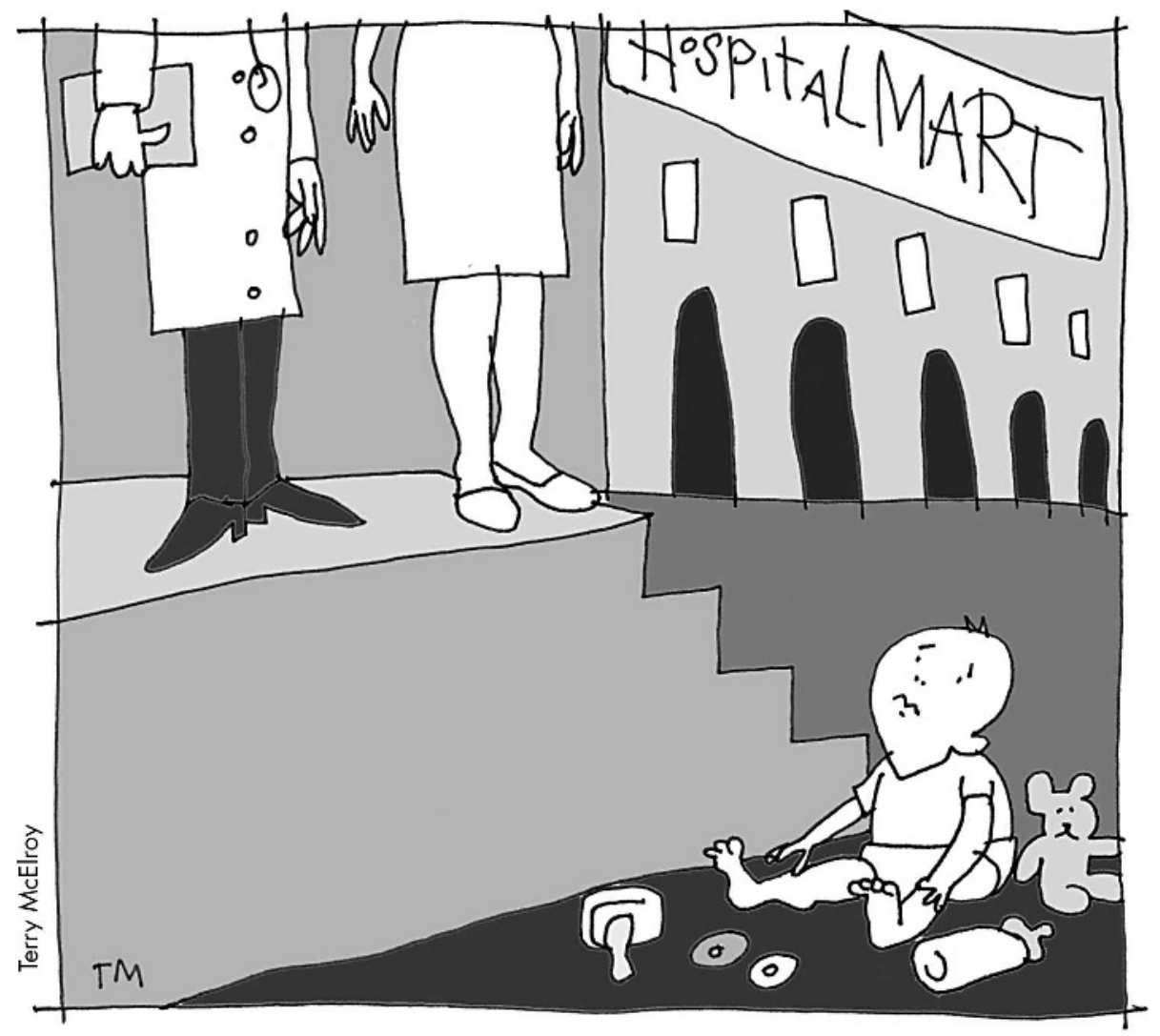

